DOI: 10.12731/2658-4034-2020-3-30-39

\title{
ВОСПИТАНИЕ И ОБУЧЕНИЕ ДЕТЕЙ В ЭПОХУ НОВЫХ ТЕХНОЛОГИЙ
}

\section{Некрасова И.В.}

\author{
МГУТУ им. К.Г. Разумовского, \\ г. Москва, Российская Федерация
}

Все это вопросы, которые нужно обсуждать. Цифровой мир уже вокруг нас, и он останется с нами. Началась новая эпоха. Перед нами стоит трудная задача: выработать приниипы воспитания детей в эпоху интернета. Нам нужно все обдумать и сформулировать ряд четких правил, которые помогут в воспитании детей, а также обеспечат их безопасность и здоровье.

Если хотите чему-то научить ребенка, вы должны освоить это сами. Лишь многолетний родительский опыт позволил мне понять мудрость такого подхода. Мы открываем для них мир. Поэтому мы должны сами разобраться и вникнуть, прежде чем учить своих детей.

Ключевые слова: ичифровые технологии; обучение детей; коммуникации в цุифровом мире; развитие, технологии и взаимосвязи.

\section{EDUCATION AND TRAINING OF CHILDREN IN THE ERA OF NEW TECHNOLOGIES}

\section{Nekrasova I.V.}

K.G. Razumovsky Moscow State University of Technologies and Management, Moscow, Russian Federation

These are all issues that need to be discussed. The digital world is already around us, and it will stay with us. A new era has begun. We face a 
difficult task: to develop the principles of education of children in the age of the Internet. We need to think about everything and formulate a number of clear rules that will help in the education of children, as well as ensure their safety and health.

If you want to teach a child something, you have to learn it yourself. Only years of parental experience allowed me to understand the wisdom of this approach. We open the world to them. Therefore, we must understand and understand ourselves before teaching our children.

Keywords: digital technologies; children's education; communications in the digital world; development; technologies and interrelations.

Сложно представить развитие человека без современных технических средств, в том числе и при реализации образовательной программы в школе, вместе с тем - «Трансгуманизация» современного образования не может не вызывать опасения. Учитель одновременно с просветительской миссией также реализует духовную миссию сохранения и совершенствования духовной природы детей, их целостности и гуманности. ФГОС подчеркивает важность обучения детей навыкам и знаниям обучающихся в сфере информационной безопасности, учитель при содействии родителей помогает школьнику адаптироваться к цифровой среде и социуму, повысить уровень информационной культуры. Важнейшая задача обеспечить безопасность и здоровье растущего человека в процессе его вхождения во взрослую жизнь, что в свою очередь требует современного подхода к воспитанию и методам обучения.

Деятельность службы психолого-педагогического сопровождения направлена на эффективное развитие, социализацию, сохранение и укрепление здоровья, защиту прав детей и подростков в условиях образовательного процесса.

Системный подход психолого-педагогического сопровождения при обучении детей грамотному использованию современных информационно-коммуникационных технологий и освоения базовых принципов безопасности интернет-пространства способствует реализации поставленных перед нами задач в практическом смысле. 
Таблицуа 1.

Плодотворное взаимодействие педагогов и родителей

\begin{tabular}{|c|c|c|c|c|c|}
\hline \multirow{2}{*}{$\begin{array}{l}\text { Воз- } \\
\text { раст- } \\
\text { ной } \\
\text { этап }\end{array}$} & \multirow{2}{*}{$\begin{array}{c}\text { Виды } \\
\text { деятель- } \\
\text { ности ре- } \\
\text { бенка }\end{array}$} & \multicolumn{3}{|c|}{ Воспитательные функции } & \multirow[b]{2}{*}{ Результат } \\
\hline & & $\begin{array}{l}\text { Педагог- } \\
\text { психолог }\end{array}$ & Педагог & Родитель & \\
\hline 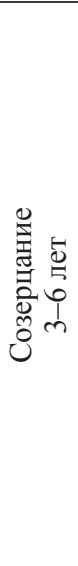 & $\begin{array}{l}\text { Межлич- } \\
\text { ностные } \\
\text { контакты; } \\
\text { подвижные } \\
\text { игры; } \\
\text { ролевые } \\
\text { игры с воз- } \\
\text { можностью } \\
\text { переноса } \\
\text { их в вир- } \\
\text { туальное } \\
\text { простран- } \\
\text { ство. }\end{array}$ & $\begin{array}{l}\text { Ознакомление с } \\
\text { нормами, в том } \\
\text { числе ограни- } \\
\text { чения времени } \\
\text { при пользова- } \\
\text { нии цифровыми } \\
\text { устройствами; } \\
\text { использова- } \\
\text { ние цифровых } \\
\text { устройств в } \\
\text { рамках обучения } \\
\text { детей; просвеще- } \\
\text { ние родителей в } \\
\text { рамках интернет } \\
\text { безопасности. }\end{array}$ & $\begin{array}{l}\text { Профилактика } \\
\text { чрезмерной } \\
\text { увлеченности } \\
\text { цифровыми } \\
\text { устройствами; } \\
\text { проведение } \\
\text { развивающих } \\
\text { занятий; про- } \\
\text { ведение ин- } \\
\text { терактивных } \\
\text { форм работ; } \\
\text { консультиро- } \\
\text { вание родите- } \\
\text { лей. }\end{array}$ & \begin{tabular}{|l|} 
Разъяснение \\
норм использо- \\
вания и ограни- \\
чения времени \\
при пользова- \\
нии цифровыми \\
устройствами в \\
соответствии с \\
возрастной нор- \\
мой ребенка; \\
конструктивное \\
использова- \\
ние цифровых \\
технологий в \\
процессе жиз- \\
недеятельно- \\
сти.
\end{tabular} & $\begin{array}{l}\text { Усвоение } \\
\text { ребенком } \\
\text { конструктив- } \\
\text { ного опыта } \\
\text { пользования } \\
\text { цифровым } \\
\text { устройством } \\
\text { в том числе } \\
\text { почерпнуто- } \\
\text { го в семье; } \\
\text { овладение } \\
\text { нормами } \\
\text { пользования } \\
\text { цифровыми } \\
\text { устройствами. }\end{array}$ \\
\hline 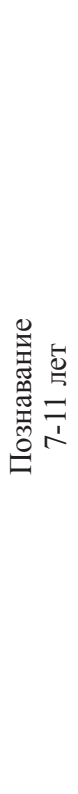 & $\begin{array}{l}\text { Учёба; } \\
\text { овладение } \\
\text { цифровы- } \\
\text { ми сред- } \\
\text { ствами } \\
\text { познания } \\
\text { для рас- } \\
\text { ширения } \\
\text { учебных } \\
\text { возможно- } \\
\text { стей. }\end{array}$ & $\begin{array}{l}\text { Диагностика } \\
\text { уровня во- } \\
\text { влеченности } \\
\text { школьников в } \\
\text { ИКТ обучение; } \\
\text { информирова- } \\
\text { ние родителей о } \\
\text { способах поло- } \\
\text { жительной адап- } \\
\text { тации детей в } \\
\text { цифровом обуче- } \\
\text { нии; проведение } \\
\text { развивающих } \\
\text { занятий во из- } \\
\text { бежание возник- } \\
\text { новения опасных } \\
\text { ситуаций при } \\
\text { пользовании } \\
\text { детьми интер- } \\
\text { нетом; консуль- } \\
\text { тирование } \\
\text { родителей стол- } \\
\text { кнувшихся с } \\
\text { трудностями. }\end{array}$ & $\begin{array}{l}\text { Ознакомле- } \\
\text { ние детей со } \\
\text { структурой } \\
\text { интернета и } \\
\text { этическими } \\
\text { нормами циф- } \\
\text { ровой комму- } \\
\text { никации. }\end{array}$ & \begin{tabular}{|l|} 
Адаптация пра- \\
вил пользования \\
цифровыми \\
устройствами \\
с учетом воз- \\
раста ребенка; \\
допустимое \\
увеличение \\
времени исполь- \\
зования цифро- \\
вых устройств \\
для обучения \\
или игр с раз- \\
умным чередо- \\
ванием видов \\
деятельности; \\
наблюдение \\
за действиями \\
ребенка в интер- \\
нете.
\end{tabular} & $\begin{array}{l}\text { Понимание } \\
\text { ребенком } \\
\text { норм по- } \\
\text { ведения в } \\
\text { интернет-про- } \\
\text { странстве и } \\
\text { этических } \\
\text { норм циф- } \\
\text { ровой ком- } \\
\text { муникации; } \\
\text { использование } \\
\text { интернет-ре- } \\
\text { сурсов для } \\
\text { обучения и } \\
\text { досуговой } \\
\text { деятельности; } \\
\text { понимание } \\
\text { структуры ин- } \\
\text { тернет-сети. }\end{array}$ \\
\hline
\end{tabular}


Окончание табл. 1.

\begin{tabular}{|c|c|c|c|c|c|}
\hline 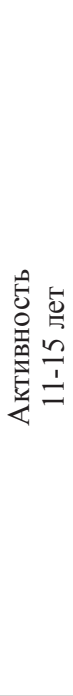 & $\begin{array}{l}\text { Общение } \\
\text { со свер- } \\
\text { стниками с } \\
\text { помощью } \\
\text { интернета; } \\
\text { освоение и } \\
\text { ведение со- } \\
\text { циальных } \\
\text { сетей. }\end{array}$ & $\begin{array}{l}\text { Диагностика } \\
\text { уровня во- } \\
\text { влеченности } \\
\text { подростков в со- } \\
\text { циальные сети; } \\
\text { консультирова- } \\
\text { ние подростков } \\
\text { и родителей, } \\
\text { столкнувшихся } \\
\text { с трудностями } \\
\text { при цифровой } \\
\text { коммуникации; } \\
\text { совместные за- } \\
\text { нятия для укоре- } \\
\text { нения навыков } \\
\text { адаптации в } \\
\text { интернет-про- } \\
\text { странстве у под- } \\
\text { ростков. }\end{array}$ & $\begin{array}{l}\text { Просвещение } \\
\text { детей и ро- } \\
\text { дителей в об- } \\
\text { ласти правил } \\
\text { безопасности } \\
\text { в интернете: } \\
\text { размещение } \\
\text { наглядной ин- } \\
\text { формации по } \\
\text { тематике; ра- } \\
\text { бота с родите- } \\
\text { лями; работа с } \\
\text { подростками; } \\
\text { ознакомление } \\
\text { с правовыми } \\
\text { аспектами, } \\
\text { возникающи- } \\
\text { ми при поль- } \\
\text { зовании } \\
\text { интернетом. }\end{array}$ & $\begin{array}{l}\text { Определение } \\
\text { четких норм при } \\
\text { пользовании } \\
\text { интернетом с со- } \\
\text { хранением дове- } \\
\text { рия к подростку; } \\
\text { снижение уров- } \\
\text { ня наблюдения } \\
\text { за подростком } \\
\text { для успешного } \\
\text { формирования } \\
\text { навыков само- } \\
\text { контроля при } \\
\text { его деятельно- } \\
\text { сти в интернет- } \\
\text { сети. }\end{array}$ & $\begin{array}{l}\text { Умение } \\
\text { подростка } \\
\text { безопасно } \\
\text { и конструк- } \\
\text { тивно ком- } \\
\text { муницировать } \\
\text { в социальных } \\
\text { сетях; ис- } \\
\text { пользование } \\
\text { интернет-ре- } \\
\text { сурсов для } \\
\text { саморазви- } \\
\text { тия и проф- } \\
\text { ориентации; } \\
\text { осмысленная } \\
\text { деятельность } \\
\text { в интернете с } \\
\text { соблюдением } \\
\text { социальных } \\
\text { и правовых } \\
\text { норм. }\end{array}$ \\
\hline 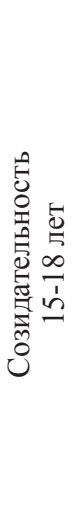 & $\begin{array}{l}\text { Формиро- } \\
\text { вание нрав- } \\
\text { ственных } \\
\text { идеалов и } \\
\text { жизненных } \\
\text { ориенти- } \\
\text { ров }\end{array}$ & $\begin{array}{l}\text { Проф- } \\
\text { ориентация } \\
\text { с помощью } \\
\text { интернет-ре- } \\
\text { сурсов; кон- } \\
\text { сультирование } \\
\text { учащихся ис- } \\
\text { пытывающих } \\
\text { трудности в } \\
\text { процессе со- } \\
\text { циализации в } \\
\text { рамках интерне- } \\
\text { та; диагностика } \\
\text { сформированно- } \\
\text { сти предыдущих } \\
\text { ступеней. }\end{array}$ & $\begin{array}{l}\text { Профильная } \\
\text { ориентация; } \\
\text { проектная дея- } \\
\text { тельность } \\
\text { как совмест- } \\
\text { ная, так и ин- } \\
\text { дивидуальная } \\
\text { с применением } \\
\text { интернет-тех- } \\
\text { нологий. }\end{array}$ & $\begin{array}{l}\text { Уменьшение } \\
\text { контроля со- } \\
\text { циальных сетей } \\
\text { подростков; } \\
\text { оказание со- } \\
\text { действия при } \\
\text { реализации } \\
\text { подростками } \\
\text { проектной де- } \\
\text { ятельности } \\
\text { посредством } \\
\text { интернет-техно- } \\
\text { логий. }\end{array}$ & $\begin{array}{l}\text { Приобрете- } \\
\text { ние подрост- } \\
\text { ком опыта в } \\
\text { реализации } \\
\text { проектной } \\
\text { деятельности } \\
\text { посредством } \\
\text { интернет- } \\
\text { технологий; } \\
\text { навык ис- } \\
\text { пользования } \\
\text { интернет- } \\
\text { ресурсов на } \\
\text { благо себе и } \\
\text { обществу. }\end{array}$ \\
\hline
\end{tabular}

Традиционные педагогические методы обуславливают необходимость проведения профилактической работы с обучающимися, важно принимать во внимание возрастные особенности детей: младшие школьники наиболее восприимчивы к игровой форме подачи материала, школьники среднего возраста к информационно-развивающим и дискуссионным методам, старшие школьники к проектным методам. 
Таблица 2.

Памятка для школьников об основных видах опасностей в сети интернет

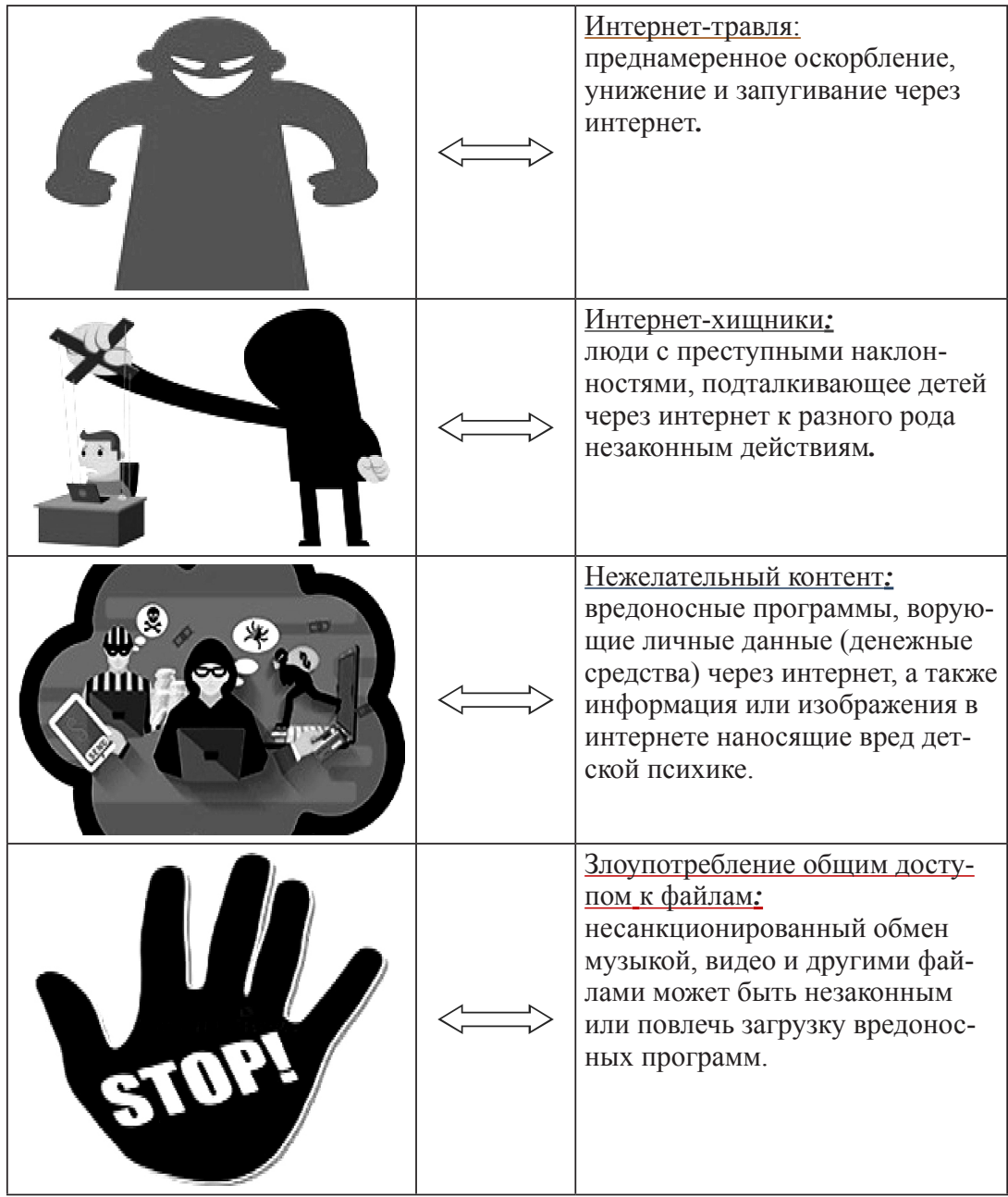

Не менее важна профилактическая работа с родителями школьников, объединенные усилия благоприятно повлияют на качество обучения детей безопасному и правильному пользованию сетью Интернет. Просветительская работа может проводиться в виде общешкольных или классных собраний для родителей с тематиче- 
скими лекциями и раздачей разработанных школой буклетов или небольших памяток, в которых можно указать перечень полезных сайтов, например:

http://xn--80aalcbc2bocdadlpp9nfk.xn--d1acj3b/personalnye dannye/; http://rkn.gov.ru/personal-data/;

http://сетевичок.pф/;

http://interneshki.ru/;

https://www.spas-extreme.ru/themes/internet bezopasnost и др.

\section{Лекция для родительского собрания}

\section{Лекция: «Будьте примером для детей в правильном использовании современных цифровых технологий и соблюдении \\ правил информационной безопасности в интернете».}

Современные дети очень отличаются от детей, которыми были мы, что продиктовано ускорением темпов развития технического прогресса. Цифровой мир требует от них необходимых навыков, умений и быстроты реакции для успешной адаптации в нем.

Дети с самого раннего возраста взаимодействуют с современными технологиями. Всевозможные гаджеты и цифровые устройства становятся их постоянными спутниками, вследствие чего они свободно ориентируется в виртуальном мире. Поэтому перед родителями и педагогами встает задача создать благоприятные условия для безопасного развития подрастающего поколения в цифровой среде.

Чтобы помочь своему ребенку, разобраться с принципами работы цифрового устройства и его возможностями, необходимо самим понимать специфику и принцип действия данного устройства, быть осведомленным в области интернета.

Необходимо рассказать вашим детям о наиболее часто встречающихся опасностях в интернете:

- интернет-травля (Кибербуллинг) - это вид психологической атаки, заключающийся в запугивании, оскорблении, унижении достоинства ради собственного развлечения; 
- интернет-хищники люди с преступными наклонностями, подталкивающие детей через интернет к незаконным действиям, пользующиеся детской доверчивостью, иногда настаивающие на личной встрече;

- нежелательный контент - бывает разного рода:

а) информация или изображения в интернете наносящие вред детской психике,

б) вредоносные программы, ворующие личные данные или денежные средства;

- злоупотребление общим доступом к файлам: несанкционированный обмен музыкой, видео и другими файлами может быть незаконным (нарушение авторского права) или повлечь загрузку вредоносных программ которые могут сломать компьютер.

Нужно объяснить ребенку, что в интернете, как и в обычной жизни существуют определенные правила поведения, которые необходимо соблюдать: нельзя распространять информацию оскорбляющую честь и достоинство других людей, создавать и распространять вредоносные программы, пытаться завладеть чужими личными данными или информацией, вести противозаконную деятельность в интернете. Загружать компьютерные программы, музыку и файлы и размещать в интернете какую-либо личную информацию о себе можно только предварительно получив одобрение от вас.

Демократический стиль семейного воспитания наиболее оптимален для решения нашей задачи. Если в семье принято интересоваться внутренним миром ребенка и общение происходит на доверительной основе, то ребенок, несомненно, спокойно отнесется к контролю его жизни и деятельности в интернете, осознавая, свою защищенность, зная, что в любой ситуации получит поддержку и помощь от вас.

Задача родителей помочь детям выработать полезные привычки и определить ряд правил.

Для сохранения здоровья детей необходимо установить временные рамки нахождения ребенка за компьютером и требовать от ребенка их соблюдения. Рекомендованные нормы: в возрасте 7-9 лет - до 1 часа 30 м в день; 10-12 лет - до 2 часов в день; 13-14 лет - до 2 
часов 30 минут; 15-17 лет до 3 часов в день, при этом обязательно делать перерывы на зарядку для глаз и разминку всего организма. Определить максимально допустимое время для игр и развлечений в сети, для развития навыков самоконтроля можно приучить ребенка пользоваться таймером. Не позволять перед сном играть в компьютерные игры.

Виртуальный мир может увлечь подростка больше чем реальный, поэтому постарайтесь с детства привить интерес ребенка к подвижным играм со сверстниками, занятиям спортом, поощряйте их продуктивные увлечения, играйте вместе в настольные и активные игры, давайте им несложные поручения по дому.

«Раньше, чем вы начнете воспитьвать своих детей, проверьте ваше собственное поведение.» А.С. Макаренко

Присмотритесь, пожалуйста, к себе, не проводите ли вы бо̀льшую часть своего сводного времени дома за смартфоном или ноутбуком? Повседневное применение цифровых устройств это данность современной жизни, важно помнить, что дети повторяют наши действия и иметь благоразумие.

Родителям на заметку:

1. Существует функция Родительский контроль, с помощью которой можно выбрать показ и открытие только безопасных для ребенка сайтов.

2. Интересуйтесь новыми друзьями детей в интернете.

3. Поддерживайте связь с классным руководителем, что позволит вам быть в курсе происходящих изменений в поведении ребенка.

Таким образом, социализирующий подход к воспитательной деятельности и адаптированность детской личности к безопасным современным виртуальным учебным технологиям обеспечит гармонично развитую, здоровую, социализированную в современном обществе личность.

\section{Список литературы}

1. Воинова О.И., Плешаков В.А. Киберонтологический подход в образовании: Монография. Норильск: НИИ, 2012. 244 с. 
2. Гобова Е., Игнатова О. Психологический портрет поколения. Типология представлений о себе // Школьный психолог. 2007. № 6. URL: http://psy.1september.ru/article.php?ID=200700612.

3. Горлова Н.А. Современные дошкольники: какие они? // Обруч: образование, ребенок, ученик. 2009. № 1. С. 3-6.

4. Захарьящева О.А Основы психолого-педагогического сопровождения детей в процессе киберсоциализации // «Ноmo Cyberus» 2019. № 1(6) 17-21 URL: http://journal.homocyberus.ru/sites/default/files/ Homo\%20Cyberus-\%E2\%84\%961\%286\%29-2019.pdf

5. Поколение в памперсах или коллективный портрет современного дошкольника. Круглый стол // Дошкольное образование. 2001. № 9. URL: https://dob.1sept.ru/article.php?ID=200100901.

6. Поколение невнимательных. Интервью с Т.Ахутиной // «Школьный психолог». URL: http://psy.1september.ru/article.php?ID=200201810.

7. Смирнова Е.О., Лаврентьева Т.В. Дошкольник в современном мире. М.: Дрофа. 2008. 270 с.

8. Ромм Т.А. Социальное воспитание: эволюция теоретических образов: монография. Новосибирск: Наука, 2007. 380 с.

\section{References}

1. Voinova O.I., Pleshakov V.A. Kiberontologicheskij podhod v obrazovanii [Cyberontological approach in education]: Monografija. Noril'sk: NII, 2012. 244 p.

2. Gobova E., Ignatova O. Psihologicheskij portret pokolenija. Tipologija predstavlenij o sebe [Psychological portrait of a generation. Typology of self-image]// Shkol'nyj psiholog. 2007. № 6. URL: http://psy.1september.ru/article.php?ID=200700612.

3. Gorlova N.A. Sovremennye doshkol'niki: kakie oni? [Modern preschoolers: what are they?] // Obruch: obrazovanie, rebenok, uchenik. 2009. № 1, pp. 3-6.

4. Zahar'jashheva O.A Osnovy psihologo-pedagogicheskogo soprovozhdenija detej v processe kibersocializacii [Fundamentals of psychological and pedagogical support of children in the process of cyber socialization]// «Homo Cyberus» 2019. № 1(6) pp 17-21 URL: http://journal.homocyberus.ru/sites/ default/files/Homo\%20Cyberus-\%E2\%84\%961\%286\%29-2019.pdf 
5. Pokolenie v pampersah ili kollektivnyj portret sovremennogo doshkol'nika. [A generation in diapers or a collective portrait of a modern preschooler] Kruglyj stol // Doshkol'noe obrazovanie. 2001. № 9. URL: https://dob.1sept.ru/article.php?ID=200100901.

6. Pokolenie nevnimatel'nyh. [ A generation of inattentive] Interv'ju s T.Ahutinoj // «Shkol'nyj psiholog». URL: http://psy.1september.ru/article.php?ID=200201810.

7. Smirnova E.O., Lavrent'eva T.V. Doshkol'nik v sovremennom mire [Preschooler in the modern world]. M.: Drofa. 2008. 270 p.

8. Romm T.A. Social'noe vospitanie: jevoljucija teoreticheskih obrazov [Social education: the evolution of theoretical images]: monografija. Novosibirsk: Nauka, 2007. 380 p. 